Ärztliche Erfahrung beschränkt sich nicht auf medizinisches Fachwissen.

Sie entsteht auch aus den mehr oder minder alltäglichen, heiter,

\title{
Ohne Stethoskop ist man kein richtiger Arzt!
}

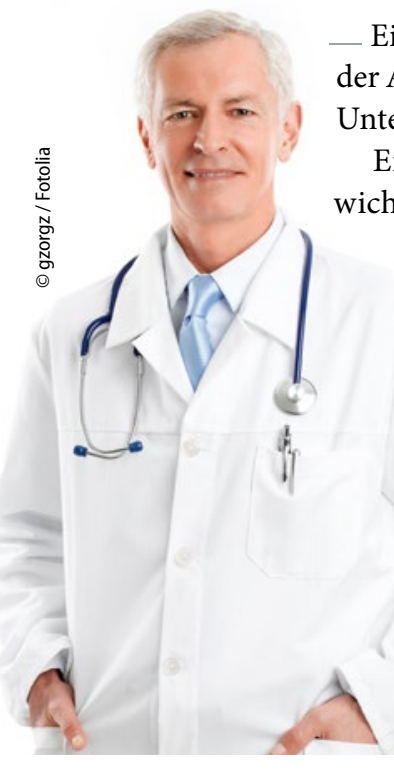

Das ist ein Arzt - ganz klar!
Eigentlich ist es ja klar: Das Stethoskops dient der Auskultation von Herz und Lunge sowie der Untersuchung von Darmgeräuschen.

Eine andere Aufgabe scheint aber noch viel wichtiger zu sein. Ich machte diese Erfahrung in einem Pflegeheim, in dem ich nicht gut bekannt war. Normalerweise war das Pflegepersonal freundlich und unterstützte mich bei der Untersuchung von Patienten. An manchen Tagen aber war man auffällig reserviert und misstrauisch. Man fragte, wer ich sei und was ich wolle. Erst als ich mich vorstellte, lief dann alles rund.

Dies ging mir bei verschiedenen Anlässen so. Ich geriet schon ins Grübeln, als es mir beim dritten $\mathrm{Mal}$ wie Schuppen von den Augen fiel: Ich hatte mein Stethoskop nicht um den Hals hängen! Ich hatte es versehentlich im Auto liegen lassen.

Wenn ich mit Stethoskop ein Pflegeheim betrete, sind die Pflegekräfte von Anfang an freundlich, kooperativ und auskunftsfreudig, auch ohne dass ich mich detailliert vorstelle. Sie ordnen dann die Situation automatisch als Arztbesuch ein und führen mich direkt zu dem Patienten, wegen dem ich gerufen wurde. So dient das Stethoskop quasi als Türöffner zum Alten-und Pflegeheim und zum Vertrauen der Pflegekräfte. Es ist wahrscheinlich seine wichtigste Funktion.

Dr. Rainer Hakimi, Stuttgart

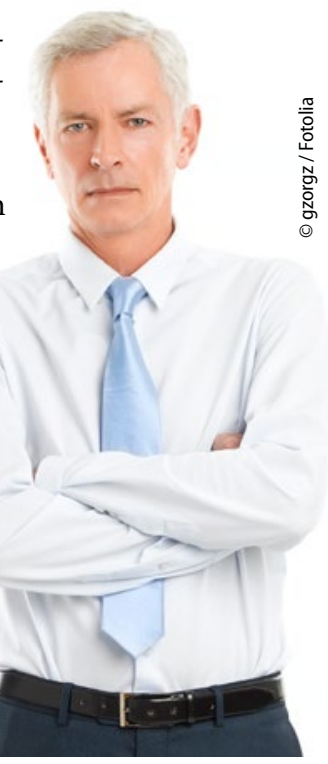

Das ist kein Arzt - auf keinen Fall!

\section{Der zweite Frühling ist ein Krankenhauserreger}

_ Sie war die letzte Patientin an diesem Vormittag - und sie war bester Laune. Das verwunderte mich etwas, denn vor drei Tagen hatte ich sie ins Krankenhaus geschickt. Eine Kardioversion bei Vorhofflattern war erforderlich gewesen. In der Regel sind ältere Patienten wenig enthusiastisch, wenn sie eingewiesen werden müssen. Sie aber saß strahlend vor mir. Zunächst schrieb ich diese Freude der zügigen Entlassung und der erfolg- reichen Therapie zu. Ein Sinusrhythmus war dokumentiert worden.

Da plötzlich änderte sich ihre Stimmung. Sie wäre so gern im Krankenhaus geblieben, stöhnte sie. Erstaunt fragte ich nach dem Grund. Da bekannte sie leicht verschämt, dass sie in der Klinik auf einen jungen und hochgewachsenen Assistenzarzt getroffen war, der sich mehrfach täglich rührend um sie gekümmert hatte. So etwas hätte sie noch nie erlebt, schwärmte sie. Nun wollte sie von mir wissen, ob dieser hübsche Herr Doktor verheiratet sei.

Ich kannte diesen Kollegen nicht und konnte somit auch keine Auskünfte über sein Privatleben geben. Ich stellte ihr aber die Gegenfrage, ob sie sich denn einen so jungen Liebhaber vorstellen könne. Sie entgegnete: „Ich bin zwar 83, aber dafür ist man nie zu alt.“

Dr. Claudia Krite-Anthes, Springe 